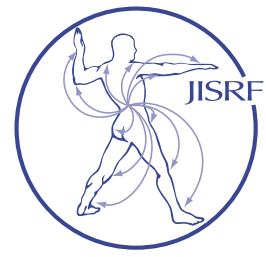

\title{
Popliteal Artery Complications of Total Knee Replacement - Our Experience In Large Volume Centre and Review of Literature
}

\author{
Nithin $S^{1}$, Reddy $A^{1}$, Muralidhar $S^{1}$
}

\begin{abstract}
We present a case report and review of literature on injury to the popliteal vessel during total knee replacement. This is rare but would be limb-threatening with devastating consequences for the patient. Because of poor collateral circulation, severe ischemia may give rise to irreversible tissue damage necessitating amputation if not adequately recognized and treated. Incidence, prognosis, treatment, potential risk factors and measures to prevent injury are discussed here. Safe and careful surgical technique will be the most effective preventative measure.
\end{abstract}

\section{Background}

Total Knee replacement is one of the successful operations performed for arthritis of knee joint. Popliteal artery occlusion after total knee arthroplasty occurs at a very low incidence $(0.03-0.17 \%)$ [1]. We here describe the incidence of popliteal artery complications in one of the large volume centre in Asia. Our case had complete occlusion of the popliteal artery at the 1st post-operative day. Our reported case of post-TKR popliteal artery thrombosis was without known risk factors. Reason for concern is because of poor collateral circulation, severe ischemia may give rise to irreversible tissue damage necessitating amputation if we do not recognize early and treat them. We reviewed cases from the literature in terms of incidence, prognosis, treatment, potential risk factors and measures to prevent injury.

\section{Case Report}

A 67 year old gentleman presented to the orthopaedic out-patient department with bilateral grade -4 osteoarthritis. On examination the patient had restriction of movements, joint line tenderness present, crepitus, no flexion deformity and bilateral varus angulation of knee of 10 degree. The patient was counselled and operated for right TKR since right knee was more symptomatic. Genesis II Posterior Stablilized by Smith \& Nephew Oxinium implant was used. Immediately in the post-operative period distal pulses were palpable. Patient was started on LMWH, but surprisingly in the post-operative day 1, ankle dorsiflexion and plantar flexion were absent. Toes were cooler and sensation was absent with the presence of femoral pulse and absence of dorsalis pedis and post-tibial pulse.

Vascular surgeon opinion was taken and a Doppler was done which showed acute arterial thrombosis in the distal 2/3 rd of the right popliteal artery with no phasic flow in the posterior and anterior tibial artery. CT angiogram

Keywords: total knee arthroplasty, popiliteal artery thrombosis, angiography

Level of Evidence: AAOS Therapeutic Level IV

Educational Value \& Significance: JISRF Level B 
showed acute thrombosis and complete occlusion of the right popliteal artery. The patient was posted for percutaneous transluminal balloon angioplasty and thrombectomy was done. Check angiogram showed good distal flow.

Now the patient is at one month follow up with intact distal pulses. Knee range of movements showed 0-90 degree with no scar issues.

\section{Discussion}

Arterial vascular injury is a rare complication of total knee arthroplasty. Although this complication being rare, it deserves attention as consequences are devastating and involves amputation of the limb. Common causes being direct sharp trauma causing laceration and haemorrhage. Atherosclerotic occlusion and thrombosis may occur due to pre-existing atherosclerosis, joint manipulation or tourniquet causing intimal damage leading to atherosclerosis. Pre-operative risk factors include history of claudication pain, rest pain, absence of distal pulses, arterial ulcers, popliteal aneurysm, previous arterial reconstruction and calcification of arteries on plain radiographs.

In a review of 9022 Total Knee Arthroplasty (TKA) patients at the Mayo Clinic, only 3 were diagnosed postoperatively with arterial sequelae [1]. In another review of 4097 patients conducted at Pennsylvania Hospital, only 7 patients $(0.17 \%)$ were found to suffer acute ischemia after the procedure [2]. Although infrequent, the arterial complications after TKA are heterogeneous; the most frequently reported are arterial thrombosis, arterial transection, arteriovenous fistula, and aneurysm formation [ 3$]$. Of these, popliteal artery thrombosis is the most frequent, accounting for $65.9 \%$ of all arterial problems [4]. In another study, 31 cases of acute popliteal artery occlusion after TKA, 11 cases $(35.5 \%)$ reportedly required amputation [].

Patients of acute limb occlusion with severe symptom such as sensory loss of more than toe, rest pain, and moderate motor deficit require emergent surgical revascularization [6]. Emergency thrombectomy would be the initial step, and if thrombus removal is not possible, surgical bypass will be the next choice. In our case, the patient presented foot coldness, decreased sensation, and paresthesias, so the thrombectomy with a Fogarty catheter for revascularization of acute arterial occlusion was immediately attempted.

In another study of 1182 patients who underwent TKA, $25 \%(6 / 24)$ of the patients with preexisting vascular disease suffered vascular injuries, whereas no patients without preexisting arterial disease had vascular injuries [7]. However, several patients without known risk factors have developed arterial ischemic complications after TKA. The assumption that post-TKA arterial complications are, for the most part, limited to patients with a previous history of arterial disease [7] now appears incomplete.

Surgical procedure is of vital importance in preventing vascular injury. During TKA operation, insertion of the retractor into the posterolateral corner of the tibia should be avoided because it is the most vulnerable area of the popliteal artery $[\underline{8}, 9]$. The popliteal artery, vein, and posterior tibial nerve usually run through the posteromedial to the lateral corner of tibia, and more than one centimetre insertion of the retractor on this site poses a great risk of direct injury to the popliteal artery [10].

There are 4 moments of TKA surgical procedure during which vessels, especially popliteal artery can be damaged: 1) at the tibial cut, 2) at the posterior cut of the femoral condyles, 3) during the application of retractor for anterior dislocation of the tibia, and 4) during placement of the knee in hyperextension after the cuts and before the application of the hardware $[\underline{8}, \underline{11}]$.

Revision surgery is associated with an approximately doubled risk of vascular injury, [12] which may reflect fixation of the artery closer to the knee joint in scar tissue [10] making it more susceptible to indirect and direct trauma. Presence of some of these risk factors may be an indication for pre-operative referral to vascular surgery with an appropriate threshold to avoid overwhelming vascular surgical services.

\section{Conclusion}

We want to conclude that from our cases, the need of pre-operative vascular Doppler in patients undergoing knee replacement arthroplasty. Prompt diagnosis depends on 2 things: clinical assessment of complications and careful Doppler assessment. Clinical assessment includes assessment for signs of vascular insufficiency such as pallor, poor capillary refill and disturbed neurological status. High index of suspicion in patients suffering from atherosclerotic conditions and co-morbid conditions. Complete assessment of risk factors for post operative arterial complication and if necessary pre-operative Doppler assessment to prevent this devastating complication. 


\section{References}

1. Turner, N. S., M. W. Pagnano, and F. H. Sim. 2001. Total knee arthroplasty after ipsilateral peripheral arterial bypass graft - acute arterial occlusion is a risk with or without tourniquet use. J. Arthroplasty 16:317-321.

2. Calligaro KD, deLaurentis DA, Booth RE, et al. Acute arterial thrombosis associated with total knee arthroplasty. J Vasc Surg 1994;20:927.

3. Langkamer VG. Local vascular complications after knee replacement: a review with illustrative case reports. Knee 2001;8:259.

4. Holmberg A, Milbrink J, Bergqvist D. Arterial complications after knee arthroplasty: 4 cases and a review of the literature. Acta Orthop Scand 1996;67:75.

5. G. Matziolis, C. Perka, and K. Labs, "Acute arterial occlusion after total knee arthroplasty," Archives of Orthopaedic and Trauma Surgery, vol. 124, no. 2, pp. 134-136, 2004.

6. Y. Sedghi, T. J. Collins, and C. J.White, "Endovascular management of acute limb ischemia," Vascular Medicine, vol. 18, no. 5, pp. 307-313, 2013.

7. Smith DE, McGraw RW, Taylor DC, et al. Arterial complications and total knee arthroplasty. J Am Acad Orthop Surg 2001;9:253

8. Ninomiya, J. T., J. C. Dean, and V. M. Goldberg. 1999. Injury to the popliteal artery and its anatomic location in total knee arthroplasty. J. Arthroplasty 14:803809.

9. Tindall, A. J., A. A. Shetty, K. D. James, A. Middleton, and K. W. Fernando. 2006. Prevalence and surgical significance of a high-origin anterior tibial artery. J. Orthop. Surg. (Hong Kong). 14:13-16.

10. Farrington, W. J., and G. J. Charnley. 2003. The effect of knee flexion on the popliteal artery and its surgical significance. J. Bone Joint Surg. Br. 85:1208;

11. Krackow K. Surgical procedure: the technique of total knee arthroplasty. St.Louis: C.V. Mosby; 1990.

12. Abularrage CJ, Weiswasser JM, DeZee KJ, Slidell MB, Henderson WG, Sidawy AN. Predictors of lower extremity arterial injury after total knee or total hip arthroplasty. J Vasc Surg 2008;47:803e8.

\section{SUBMISSION HISTORY}

Submitted January 21, 2018

Reviewed February 2, 2018

Revised February 25, 2018

Accepted March 23, 2018

Published September 30, 2018

\section{AUTHOR AFFILIATIONS}

1 Dr Sunku Nithin, Dr A V Guruva Reddy, Dr Sagi Muralidhar

Sunshine Hospital, Penderghast Road, Opposite Parsi Dharamsala, Paradise,

Secunderabad, Telangana 500003, India

(Direct inquires to Sunku Nithin, drsnithin@gmail.com)

\section{AUTHOR DISCLOSURES}

The authors declare that there are no disclosures regarding the publication of this paper.

\section{COPYRIGHT \& OPEN ACCESS}

(C) 2018 Nithin, Reddy, Muralidhar. All rights reserved.

Authors retain copyright and grant the journal right of first publication with the work. Reconstructive Review is an open access publication and follows the Creative Commons Attribution-NonCommercial CC BY-NC. This license allows anyone to download works, build upon the material, and share them with others for non-commercial purposes as long as they credit the senior author, Reconstructive Review, and the Joint Implant Surgery \& Research Foundation (JISRF). An example credit would be: "Courtesy of (senior author's name), Reconstructive Review, JISRF, Chagrin Falls, Ohio".

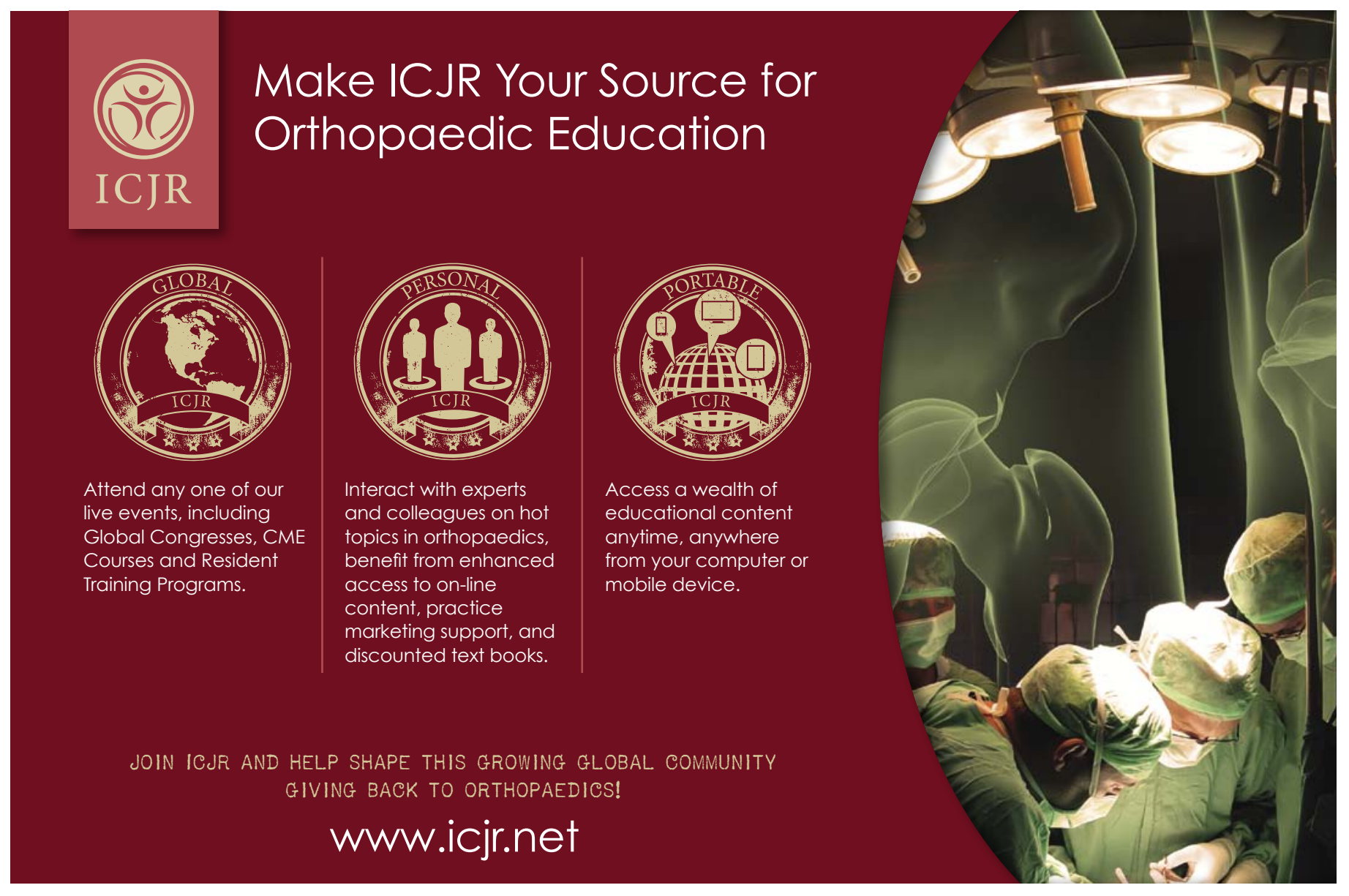

